\title{
Alterations in B Cell Compartment Correlate with Poor Neutralization Response and Disease Progression in HIV-1 Infected Children
}

OPEN ACCESS

Edited by:

Francesca Chiodi,

Karolinska Institute (KI), Sweden

Reviewed by:

Lucia Lopalco,

San Raffaele Hospital (IRCCS), Italy

Yolande Richard,

Institut National de la Santé et de la Recherche Médicale, France

*Correspondence:

Kalpana Luthra

kalpanaluthra@gmail.com

tPresent address:

Omkar Chaudhary,

Division of Infectious Diseases, Boston Children's Hospital, Harvard

Medical School, Boston, MA, United States;

Muzamil Ashraf Makhdoomi, Government College for Women, Cluster University Srinagar, Srinagar, Jammu and Kashmir, India

Specialty section: This article was submitted to HIV and AIDS,

a section of the journal

Frontiers in Immunology

Received: 30 September 2017 Accepted: 17 November 2017 Published: 01 December 2017

Citation: Aggarwal H, Khan L, Chaudhary O, Kumar S, Makhdoomi MA, Singh $R$,

Sharma K, Mishra N, Lodha R, Srinivas M, Das BK, Kabra SK and Luthra K (2017) Alterations in B Cell

Compartment Correlate with

Poor Neutralization Response and Disease Progression in HIV-1 Infected Children.

Front. Immunol. 8:1697. doi: 10.3389/fimmu.2017.01697

\author{
Heena Aggarwal ${ }^{1}$, Lubina Khan ${ }^{1}$, Omkar Chaudhary ${ }^{1 \dagger}$, Sanjeev Kumar', \\ Muzamil Ashraf Makhdoomi it, Ravinder Singh ${ }^{2}$, Kanika Sharma $^{3}$, Nitesh Mishra', \\ Rakesh Lodha ${ }^{2}$, Maddur Srinivas ${ }^{3}$, Bimal Kumar Das ${ }^{4}$, Sushil Kumar Kabra ${ }^{2}$ \\ and Kalpana Luthra ${ }^{*}$
}

\begin{abstract}
Department of Biochemistry, All India Institute of Medical Sciences, New Delhi, India, ${ }^{2}$ Department of Pediatrics, All India Institute of Medical Sciences, New Delhi, India, ${ }^{3}$ Department of Pediatric Surgery, All India Institute of Medical Sciences, New Delhi, India, ${ }^{4}$ Department of Microbiology, All India Institute of Medical Sciences, New Delhi, India
\end{abstract}

Several B cell defects are reported in HIV-1 infected individuals including variation in B cell subsets, polyclonal B cell activation and exhaustion, with broadly neutralizing antibodies elicited in less than 10-20\% of the infected population. HIV-1 disease progression is faster in children than adults. B Lymphocyte Stimulator (BLyS), expressed on dendritic cells (DCs), is a key regulator of B cell homeostasis. Understanding how DCs influence B cell phenotype and functionality (viral neutralization), thereby HIV-1 disease outcome in infected children, is important to develop interventional strategies for restoration of $\mathrm{B}$ cell function. In this study, a total of 38 vertically transmitted HIV-1 infected antiretroviral therapy (ART) naivve children and 25 seronegative controls were recruited. Based on the CD4 counts and years post-infection, infected children were categorized as long-term non-progressors (LTNPS) $(n=20)$ and progressors $(n=18)$. Eight of these progressors were followed up at 6-12 months post-ART. Percentages (\%) of DCs, B cell subsets, and expression of BLyS on DCs were analyzed by flow-cytometry. Plasma levels of B cell growth factors were measured by ELISA and viral neutralization activity was determined using TZM-bl assay. Lower (\%) of myeloid DCs (mDCs), plasmacytoid DCs, and high expression of BLyS on mDCs were observed in HIV-1 infected progressors than seronegative controls. Progressors showed lower \% of naive B cells, resting memory B cells and higher $\%$ of mature activated, tissue-like memory B cells as compared to seronegative controls. Higher plasma levels of IL-4, IL-6, IL-10, and IgA were observed in progressors vs. seronegative controls. Plasma levels of lgG were high in progressors and in LTNPs than seronegative controls, suggesting persistence of hypergammaglobulinemia at all stages of disease. High plasma levels of BLyS in progressors positively correlated with poor viral neutralizing activity. Interestingly on follow up, treatment naïve progressors, post-ART showed increase in resting memory B cells along with reduction in plasma BLyS levels that correlated with improvement in viral neutralization. This is the first study to demonstrate that reduction in plasma BLyS levels correlates with restoration of B cell function, in terms of viral neutralization in HIV-1-infected children.

Keywords: HIV-1, dendritic cells, B lymphocyte stimulator, B cells, long-term non-progressors, progressors, neutralizing activity 


\section{INTRODUCTION}

Slower disease progression or suppression of viremia in HIV-1 infected individuals is linked with "protective" host factors like the 32 base pair deletion of the co-receptor CCR5, and the presence of specific human leukocyte antigen (HLA) class I alleles (HLA-B57 and HLA-B27) (1-3). However, progression rates are not much influenced by HLA class I variation in pediatric infection, wherein AIDS typically develops faster than in adults $(2,4-6)$. Infected children have persistent high viremia, delayed viral set point, presumably in part due to an immature immune system, and the rapid expansion of $\mathrm{CD}^{+} \mathrm{T}$ cells $(3,7,8)$. Also, in early stages of life, lack of immunological memory and tolerogenic state of innate and adaptive immunity, render the host more susceptible to infectious pathogens like HIV-1 (7). Despite this, some infected children $(<1 \%)$ maintain stable CD4 counts and remain asymptomatic for more than 7 years of infection [longterm non-progressors (LTNPs)] and their immune activation is low (8-10). Innate immunity is the earliest defense mechanism preventing microbial infection and alterations in which may impact mother to child transmission and disease outcome (11). The pediatric model affords several advantages for studying virushost interactions, including the information on virus source and time of exposure (11). In infants who are exposed to HIV-1, innate immunity is of particular relevance in conferring protection since the adaptive immune system is still under development $(12,13)$. There is a paucity of information on the interactions between innate and adaptive immune response in HIV-1 infection that influences disease progression in infected children.

Dendritic cells (DCs) are one of the earliest cell types that encounter HIV-1 at mucosal sites (14). Given that DCs are professional antigen-presenting cells and form a critical link between the innate and the adaptive immune responses, it is likely that they possess an inherent capacity to modulate the balance between tolerance and protection (15). The two major DC populations in peripheral blood are CD11 $\mathrm{c}^{+}$myeloid DCs (mDCs) and $\mathrm{CD} 123^{+}$ plasmacytoid DCs (pDCs) (16-18). Further, subsets of mDCs, i.e., BDCA- $3^{+}$DCs and BDCA- ${ }^{+}$DCs have been described (19, 20). In HIV-1-infected individuals, a reduction in circulating $\mathrm{mDC}$ subsets and $\mathrm{pDC}$ has been shown earlier $(19,21)$. Decrease in $\mathrm{mDC}$ subsets has also been observed during advanced SIV infection (22). The overall outcome of HIV-1 infection may depend on the ability of the host to maintain DC homeostasis at mucosal sites. A number of B cell alterations are seen in HIV-1 infected individuals like polyclonal activation, exhaustion or loss of memory B cells, and a global impairment of antibody (Ab) responses (23-25). These B cell perturbations lead to functional abnormalities, as demonstrated by hypergammaglobulinemia, decreased $\mathrm{B}$ cell responsiveness to both $\mathrm{T}$ cell-dependent and $\mathrm{T}$ cell independent antigens and compromised responses to vaccination. The specific mechanisms contributing to $\mathrm{B}$ cell abnormalities are only partially known, and multiple factors may account for their dysfunction (25-27). HIV-1 driven alteration of the cytokine and chemokine milieu has been described as a predisposing factor of B cell dysfunction (28). In a recent study by Mabuka et al. (29) conducted in 22 women from the KwaZuluNatal province of South Africa, pre- and post-HIV-1 subtype C infection, B cell defects were seen in hyperacute HIV-1 infection in antiretroviral naïve status, that are abrogated with immediate treatment, implicating the influence of viremia on B cell alterations. However, higher levels of CXCL13 and not B cell changes or viremia during hyperacute infection were found to be associated with emergence of cross-neutralizing antibodies within 1 year of infection (29).

The DCs influence mucosal B cell responses against HIV-1 through contact and/or production of B cell growth factors such as B Lymphocyte Stimulator/B cell-activating factor belonging to the TNF family (BLyS/BAFF), which in turn may lead to skewed $\mathrm{B}$-cell subsets and poor outcome of B-cell responses against the virus, thereby modulating threshold toward disease progression (30, 31). Study on HIV-1/SIV infections in non-pathogenic animal models and from mucosal challenges in non-human primates suggests the importance of maintaining mucosal immunity in conferring protection (32).

Although there is sufficient B cell functionality to mount broadly neutralizing antibodies (bnAbs) against HIV-1, only a small proportion of HIV-1 infected individuals elicit bnAb responses (33). HIV-1 specific bnAbs play a crucial role in viral neutralization and mediate effector functions such as Ab-dependent cell-mediated cytotoxicity (ADCC) and thereby augment antiviral responses (34). Viral determinants are not the only factors driving infant neutralizing antibody ( $\mathrm{nAb}$ ) breadth, rather host determinants are equally important. Defining the immune correlates that influence the generation of bnAbs will contribute to the design of efficient immunotherapies (10).

There is limited information on phenotypic and functional defects of DCs, B cells and DC mediated alterations in B cell subsets in pediatric HIV-1 infection and disease progression (15, $17,25,27,28,35,36)$. Independent studies have reported lower percentages of DCs and linked DC-mediated alterations of B cell subsets with faster disease progression (32), while preservation of HIV-1 specific memory B cells is associated with efficient viral neutralization in elite controllers (ECs) (37). Delineating the innate mechanisms that contribute to improvement of B cell function in HIV-1 infected children can provide new leads into vaccine development.

This is a comprehensive study undertaken to evaluate alterations in innate and humoral immune responses by profiling DCs and $B$ cell subsets and their modulatory effect on viral neutralizing antibody response in chronic HIV-1C infected children at different stages of disease progression.

\section{MATERIALS AND METHODS}

\section{Study Subjects}

A total of $38 \mathrm{HIV}$-1-infected children and 25 seronegative controls were recruited in this study. After obtaining written informed consent from parents/legally accepted representative (LAR), blood samples (2-4 mL) of HIV-1 infected children and seronegative donors were collected in ethylenediaminetetraacetic acid (EDTA) vacutainers from the Pediatrics out Patient Department (OPD) and Pediatrics Surgery OPD, respectively, at the All India Institute of Medical Sciences (AIIMS), New Delhi. 
The HIV-1 infected ART naïve children were grouped into 20 LTNPs and 18 progressors of which 8 progressors were followed up post 6-12 months of initiation of ART. HIV-1 infected asymptomatic ART naïve children with $>7$ years of infection, with CD4 counts $\geq 450$ cells $/ \mu \mathrm{L}$ at the time of recruitment, and stable for the last 18 months, were categorized as LTNPs. Progressors were defined as infected children (age $<5$ years) with CD 4 count $\leq 25 \%$ and children (age $>5$ years) with CD 4 counts $\leq 450$ cells $/ \mu \mathrm{L}$ or declining since 18 months prior to recruitment $(10,38,39)$. The ART regimen for the infected children on treatment included a combination of two nucleoside reverse transcriptase inhibitors (NRTIs)-Lamivudine with Zidovudine or Stavudine and one non-nucleoside reverse transcriptase inhibitor (NNRTI)Nevirapine or Efavirenz, as per the national guidelines.

\section{CD4 Count and Viral Load Measurement}

HIV-1 viral loads were determined in plasma samples of infected children by quantitative reverse transcriptase polymerase chain reaction (Quantitative RT-PCR) (Roche COBAS TaqMan HIV-1 v2.0; Roche Diagnostics). The lower detection limit of the assay was $47 \mathrm{HIV}-1$ RNA copies/mL. The $\mathrm{CD}^{+}{ }^{+} \mathrm{T}$ cell counts were assessed by flow-cytometric analysis (BD Biosciences) at the Department of Microbiology, AIIMS.

\section{Measurement of Plasma Levels of IgG, IgA, BLyS, IL-4, IL-6, IL-10}

Plasma levels of IL-4, IL-6, IL-10 and BLyS were measured with a commercially available ELISA kit (R\&D Systems) according/to the manufacturers' protocol. Plasma levels of IgA were measured using a commercially available kit from Immunology Consultants Laboratory, Inc. Plasma levels of IgG were determined using ELISA kit (Raybiotech) according to the manufacturer's protocol.

\section{Flow-Cytometric Analysis of DC Subsets, Membrane Expression of BLyS, and B Cell Subsets by Surface Staining of DC and B Cell Subsets}

Whole blood $(100 \mu \mathrm{L})$ was subjected to surface staining by adding the following Ab cocktails: Lineage-1 (cocktail of CD3, CD14, CD16, CD19, CD20, and CD56) FITC, CD11c/CD123 APC, HLA-DR PerCPCy5.5, BLyS PE. The Lineage Cocktail 1 used in FCM analysis contained Ab clones that, in combination, stained lymphocytes, monocytes, eosinophils, and neutrophils. Cells that were negative for staining with Lin 1 and positive for HLA-DR, CD 11c/CD123 were identified as DCs. For B cell phenotyping, cocktail of antibodies used was CD19 FITC, CD21 PE, CD27 APC and CD10 PerCPCy5.5. Isotype controls used for antihuman CD11c, CD123, and CD10 antibodies are shown in supplementary data (Figure S1 in Supplementary Material). The panel of antibodies used to identify the subsets of DCs and B cells is detailed in Table S1 in Supplementary Material. Tubes were vortexed and incubated at room temperature for $30 \mathrm{~min}$. After incubation, red cells were lysed using BD lysing solution followed by washing with $2 \mathrm{ml}$ of $1 \mathrm{X}$ phosphate buffered saline. Cell pellets were resuspended in $300 \mu \mathrm{l} \%$ paraformaldehye and stored in dark at $4^{\circ} \mathrm{C}$, prior to flow-cytometric analysis. Acquisition was performed on FACS-CANTO using FACSDIVA as software. A total of 100,000 events were acquired for each sample during FCM analysis. Figure 1 shows representative gating strategy of DC subsets, Figure 3 shows representative gating strategy of B cell subsets.

\section{Viral Neutralization Assay}

Plasma samples from 28 antiretroviral naïve (10 LTNPs, 18 Progressors) HIV-1 infected children at baseline, and 8 followup samples were assessed for cross neutralization activity in a single-round HIV-1 envelope pseudovirus (200 TCID $\left._{50}\right)$ infection of TZM-bl cells as described elsewhere (40). Viruses $(n=11)$ of tier 1 and 2 belonging to different clades (41) (Table S2 in Supplementary Material) were used to measure viral neutralizing activity. HIV-1 envelope pseudoviruses were produced by co-transfecting HEK293T cells with HIV-1 envelope containing expression vector and an HIV-1 genomic vector (pSG3 delta env backbone).

\section{Heat-Map Analysis Based on Clustering of Plasma Neutralization Activity Data}

The plasma $\mathrm{nAb}$ responses at all time-points was determined by heat-map tool using hierarchical clustering, freely available at HIV-1 database (https://www.hiv.lanl.gov/content/sequence/ HEATMAP/heatmap.html), that clustered the 28 baseline and 8 follow up HIV-1-infected samples and $11 \mathrm{HIV}-1$ viruses on the basis of natural $\log \mathrm{ID}_{50}$ values.

\section{Statistical Analysis}

Results are depicted as median and interquartile ranges. Spearman Rank test was used to evaluate the correlation between plasma levels of BLyS and geometric mean titers (GMTs) of neutralization in the infected children. $p$-values $<0.05$ were considered significant. For comparison of test values between seronegative donors, LTNPs and progressors, Mann-Whitney test was used. For analysis of paired samples of HIV-1-infected children before and after initiation of ART, Wilcoxon signed rank test was applied. Analyses were performed using GraphPad PRISM 5.0 for Windows (GraphPad Software Inc.).

\section{RESULTS}

\section{Sociodemographic and Clinical Characteristics of HIV-1 Infected Children}

A total of 38 ART naïve HIV-1 chronically infected children, and 25 healthy seronegative controls were recruited for the study. The HIV-1-infected children were documented to have acquired the infection through perinatal mode of transmission. All study groups were similar with respect to age, sex, race and modes of HIV-1 acquisition. Based on the years post infection and CD4 counts, they were categorized into ART-naïve 20 LTNPs and 18 progressors. Among the progressors, 8 were followed up 6-12 months after ART initiation. Mean age of progressors was lower than that of LTNPs $(p<0.0001)$. Progressors showed significantly lower CD4 counts $(p=0.001)$ and higher 

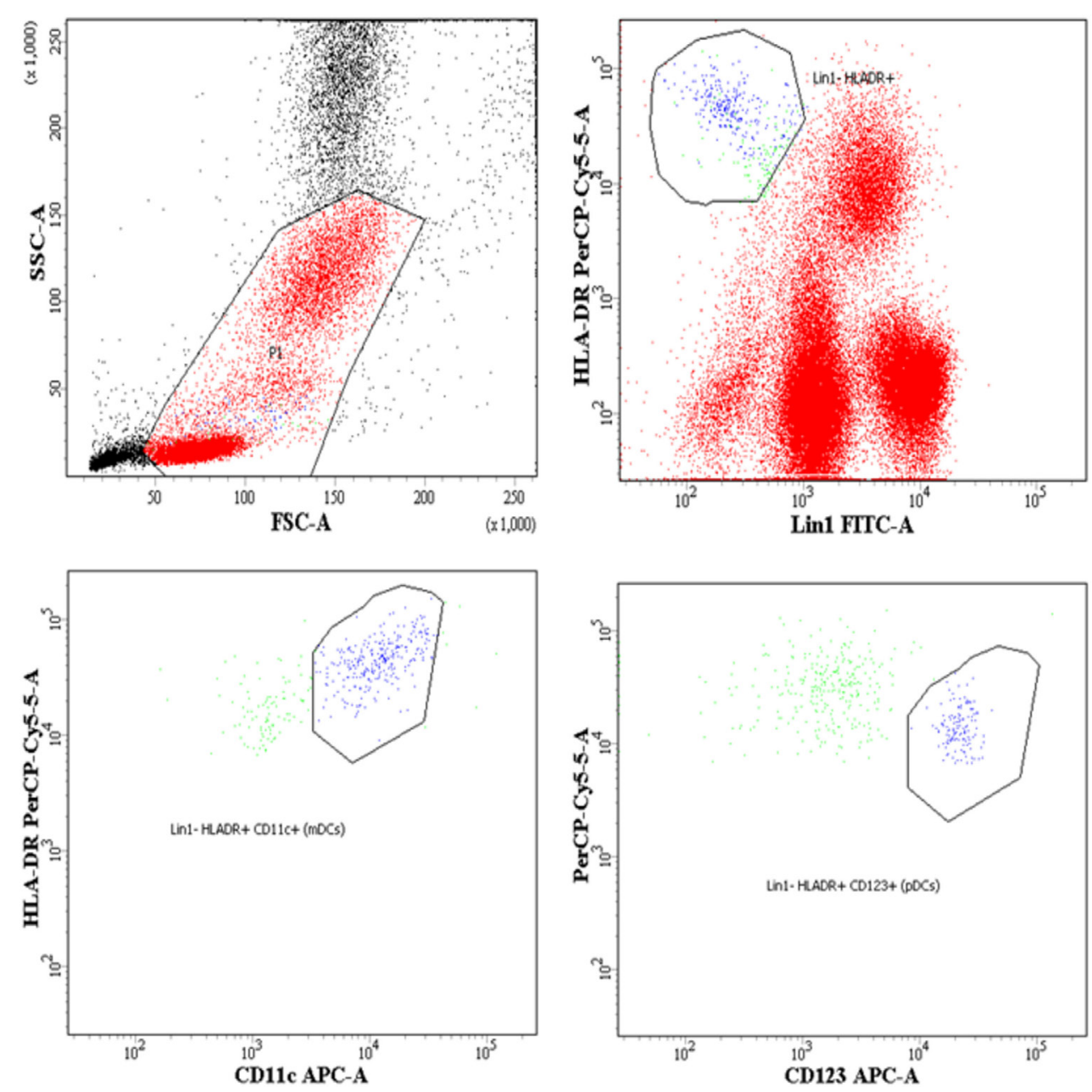

FIGURE 1 | Flow-cytometric analysis of dendritic cell (DC) subsets in whole blood and surface expression of B lymphocyte stimulator (BLyS) on myeloid DCs (mDCs) and plasmacytoid DCs (pDCs). Representative gating strategy for DC subsets. Cells were gated on whole blood, mDCs were defined as Lin1 (CD3, CD14, CD16, CD19, CD20, and CD56)- HLADR ${ }^{+}$CD11 ${ }^{+}$, pDCs were defined as Lin1- HLADR ${ }^{+}$CD123 $^{+}$. Percentages of mDCs and pDCs are expressed as \% of whole blood (leukocytes), which includes lymphocytes, monocytes, and granulocytes.

viral loads than that observed in LTNPs $(p=0.0002)$. The demographic profile of the HIV-1-infected children is summarized in Table 1.

\section{Lower Percentages of $\mathrm{mDCs}$ and $\mathrm{pDCs}$ and High Expression of BLyS on Surface of mDCs Observed in Progressors}

The DCs gating experiments shown in Figure 1 are described in the legends. Progressors showed significantly lower $\%$ of mDCs as compared to seronegative controls $(p=0.015)$, with no significant differences between the LTNPs and seronegative controls (Figure 2A). Significantly lower $\%$ of pDCs was observed in progressors $(p<0.0001)$ and LTNPs $(p<0.0001)$ as compared to seronegative controls (Figure 2B). Surface expression of BLyS on mDCs was found to be significantly higher in progressors $(p=0.021)$ as compared seronegative controls
TABLE 1 | Demographic and clinical profile of the HIV-1-infected children.

\begin{tabular}{|c|c|c|c|}
\hline Parameter & LTNPs $(n=20)$ & $\begin{array}{l}\text { Progressors pre-ART } \\
\qquad(n=18)\end{array}$ & $p$-Value \\
\hline Age $(Y)$, median (range) & $9.5(6.9-14)$ & $3(1.2-7)$ & - \\
\hline $\begin{array}{l}\text { CD4 count, cells } / \mu \mathrm{L} \text {, } \\
\text { median (range) }\end{array}$ & 780 (450-1964) & $\begin{array}{c}355 \text { [age }>5 \text { years] } \\
(103-356)\end{array}$ & 0.001 \\
\hline CD4 \% (range) & - & $\begin{array}{c}20 \% \text { [age }<5 \text { years] } \\
(11-24 \%)\end{array}$ & \\
\hline $\begin{array}{l}\text { Viral load, RNA copies/ } \\
\mathrm{mL} \text {, median (range) }\end{array}$ & $\begin{array}{c}23,400 \\
\left(4,080-2.6 \times 10^{5}\right)\end{array}$ & $\begin{array}{c}585,680 \\
\left(61835-3.15 \times 10^{7}\right)\end{array}$ & 0.0002 \\
\hline
\end{tabular}

n, number of subjects; $Y$, years; LTNPs, long-term non-progressors.

(Figure 2C). Surface expression of BLyS on pDCs did not differ significantly among seronegative controls and HIV-1 infected LTNPs and Progressors (Figure 2D). 


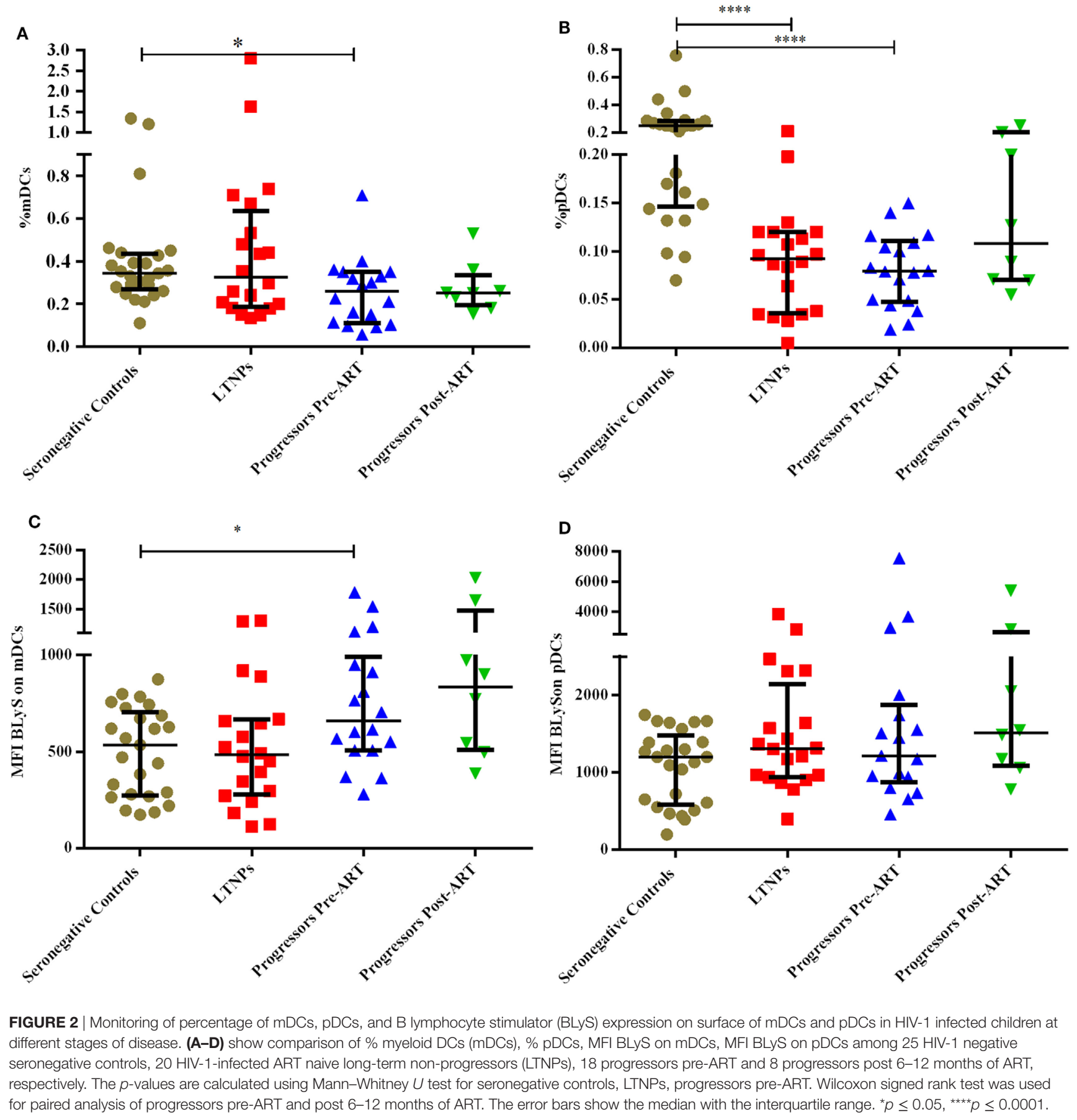

\section{Lower \% of Naïve, Resting Memory (RM) B Cells and Higher \% of Mature Activated (MA), Tissue-Like Memory (TLM) B Cells Observed in Progressors}

The B cells gating experiments shown in Figure 3 are described in the legends. The percentages of naive $B$ cells in all HIV-1-infected children recruited in this study were lower irrespective of disease stage than those observed in HIV-1 seronegative controls, reaching statistical significance in both LTNPs $(p=0.016)$ and progressors $(p=0.031)$ (Figure 4A). Further, $\%$ of TLM B cells $(p=0.0003)$ and mature activated (MA) B cells $(p=0.041)$, remained significantly higher in progressors compared to seronegative controls (Figures 4B,D). A significant decrease in resting memory (RM) B cell frequencies (Figure 4C) was observed in infected progressors as well as 

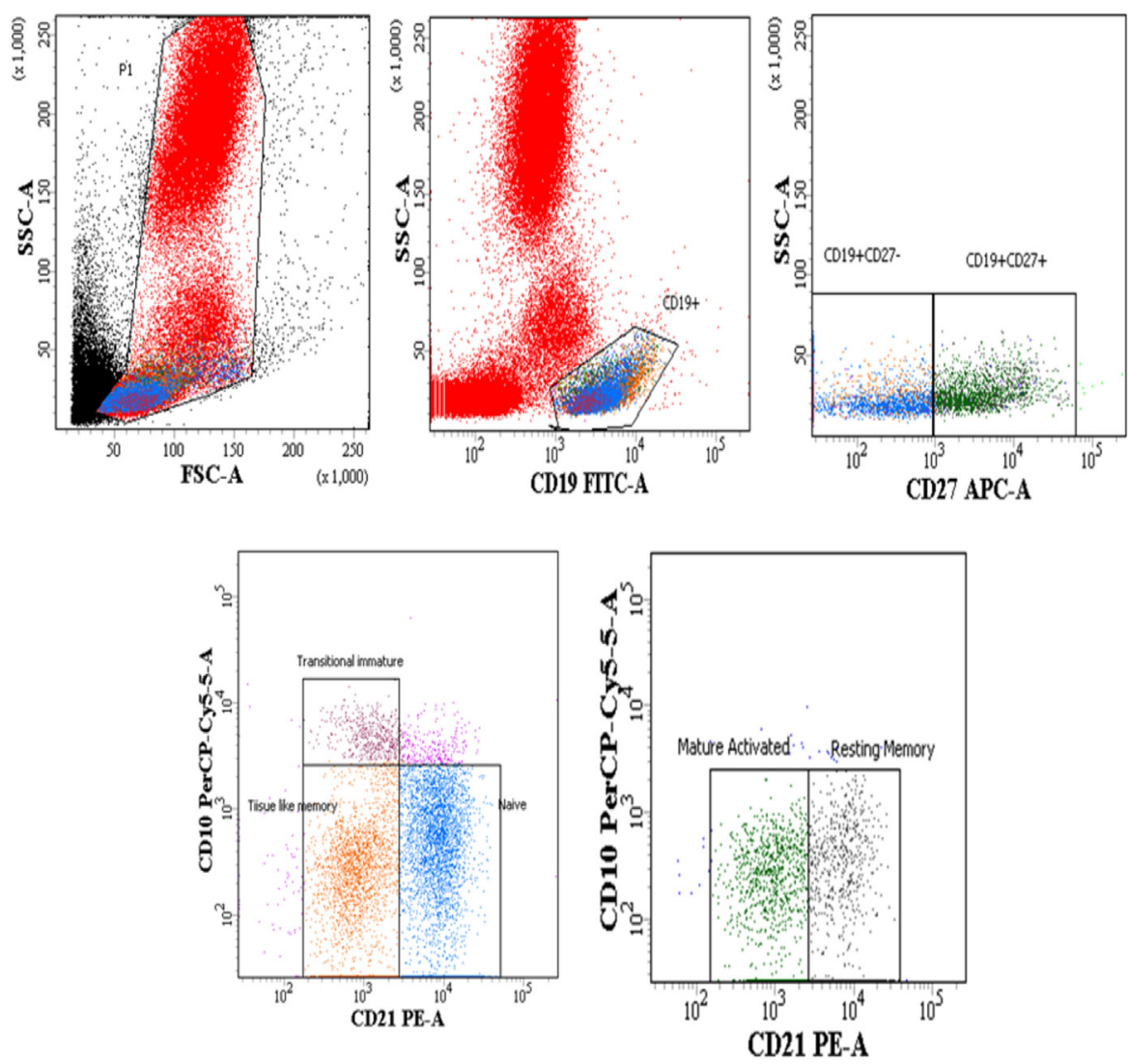

FIGURE 3 | Flow-cytometric analysis of B cell subsets (gated on CD19+ B cells) in HIV-1-infected children at different stages of disease. Representative gating strategy for naïve B cells (CD19+ CD27- CD10- CD21+), tissue-like memory (TLM) B cells (CD19+ CD27- CD10- CD21-), transitional immature (TI) B cells (CD19+ $\left.\mathrm{CD}^{-} 7^{-} \mathrm{CD} 0^{+} \mathrm{CD} 21^{-}\right)$resting memory (RM) B cells (CD19+ CD27+ CD10- CD21+) and mature activated (MA) B cells as (CD19+ CD27+ CD10- CD21-). Lower left panel shows naïve, TI and TLM B cells gated on CD19+ CD27- cells, lower right panel shows mature activated and resting memory $B$ cells gated on CD19 $^{+}$CD27+ cells. Percentages of B cell subsets are expressed as \% of CD19+ B cells.

LTNPs $(p=0.032)$ compared to seronegative controls, with a more prominent decrease seen in progressors $(p=0.0015)$, indicating severe loss of resting memory B cells in progressors. Upon initiation of ART in eight progressors, resting memory $B$ cells were significantly restored $(p=0.015)$ (Figure 4C; Figure S2A in Supplementary Material).

\section{Plasma Levels of B-Cell Growth Factors (BLyS, IL-4, IL-6, IL-10), IgA and IgG in HIV-1-Infected Children at Different Stages of Disease}

Plasma levels of BLyS were higher in progressors compared to LTNPs and seronegative controls $(p=0.0007)$ (Figure 5A). Levels of BLyS decreased upon initiation of ART in progressors $(p=0.007)$ and were comparable with the levels in LTNPs (Figure 5A; Figure S2B in Supplementary Material). The plasma levels of IL-6 $(p=0.008)$, IL-4 $(p=0.019)$, IL-10 $(p=0.026)$, and $\operatorname{IgA}(p=0.044)$ were higher in progressors than in seronegative controls (Figures 5B-E). The plasma IgG levels were high in progressors $(0.0008)$ and in LTNPs $(p=0.014)$ as compared to seronegative controls (Figure 5F) while in progressors post 6-12 months of ART, decrease in levels of IL-4 $(p=0.039)$, IL-10 $(p=0.039)$, and $\operatorname{IgG}(p=0.023)$ were observed (Figures 5C,D,F).

\section{Low ID $_{50}$ Titers of Neutralizing Antibodies (nAbs) in Progressors Pre-ART vs. LTNPs and Significant Improvement in NAb Titers Post-ART}

We compared the viral neutralization activity of plasma antibodies against a panel of 11 tier 1 and tier 2, clade A, B, and C viruses from 10 ART naïve LTNPs and 18 progressors pre-ART and follow-up samples of 8 progressors post 6-12 months of ART. Higher neutralization titers were observed in LTNPs as compared to progressors (darker the color, greater the $\mathrm{ID}_{50}$ values) (Figure 6A; Figure S3 in Supplementary Material). Progressors did not elicit effective Ag-specific NAb responses. A substantial improvement in viral neutralizing activity was observed on initiation of ART in eight progressors (Figure 6B; Figure S3 in Supplementary Material). 

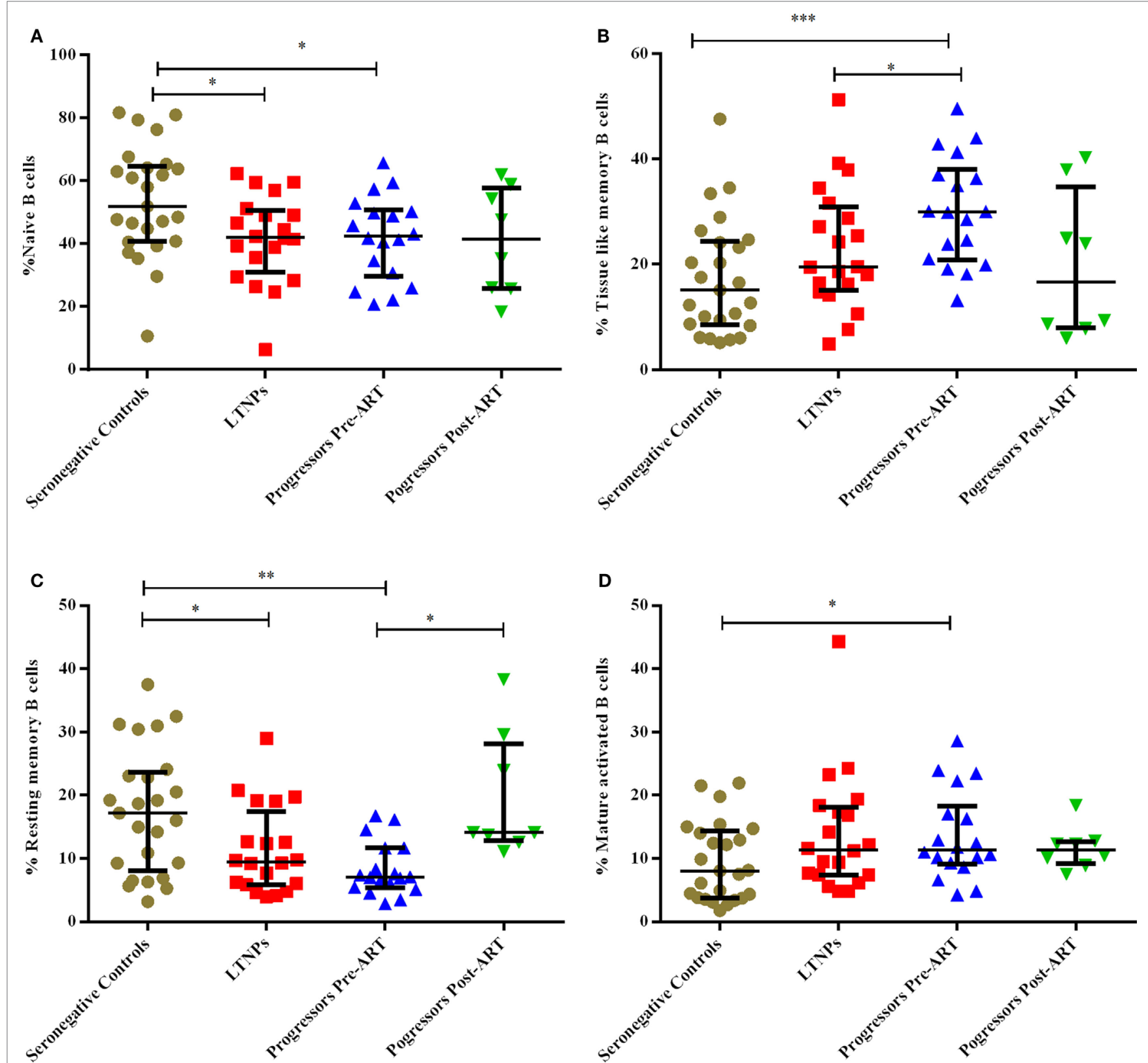

FIGURE 4 | Monitoring of percentage of B cell subsets in HIV-1 infected children at different stages of disease. (A-D) show comparison of naïve B cells, tissue-like memory B cells, resting memory B cells, mature activated B cells among 25 HIV-1 negative seronegative controls, 20 HIV-1-infected ART naive long-term non-progressors (LTNPS), 18 progressors pre-ART and 8 progressors post 6-12 months of ART, respectively. The $p$-values are calculated using Mann-Whitney $U$ test for seronegative controls, LTNPs, progressors pre-ART, Wilcoxon signed rank test was used for paired analysis of progressors pre-ART and post 6-12 months ART. The error bars show the median with the interquartile range. ${ }^{*} p \leq 0.05,{ }^{* *} p \leq 0.01,{ }^{* \star *} p \leq 0.001$.

\section{Progressors Depicted Lower GMTs Compared to LTNPs against a Panel of 11 Pseudoviruses}

We compared GMTs using ID $_{50}$ values of the plasma neutralizing activity of 10 ART naïve LTNPs and 18 progressors pre-ART and follow-up samples of 8 progressors post 6-12 months of ART. The LTNPs exhibited significantly higher GMTs of neutralizing activity compared to progressors $(p=0.001)$ against 11 tier 1 and 2 viruses of different clades (Figure 7A). To calculate \% of viruses neutralized, $\mathrm{ID}_{50}>300$ was taken as cut off value. Progressors exhibited lower \% of viruses neutralized vs. LTNPs $(p=0.009)$ (Figure 7B) and there was a significant improvement in GMTs $(p=0.015)$ (Figure 7A; Figure S2C in Supplementary Material) and $\%$ of viruses neutralized $(p=0.015)$ (Figure 7B; Figure S2D in Supplementary Material) in progressors, upon ART initiation. 

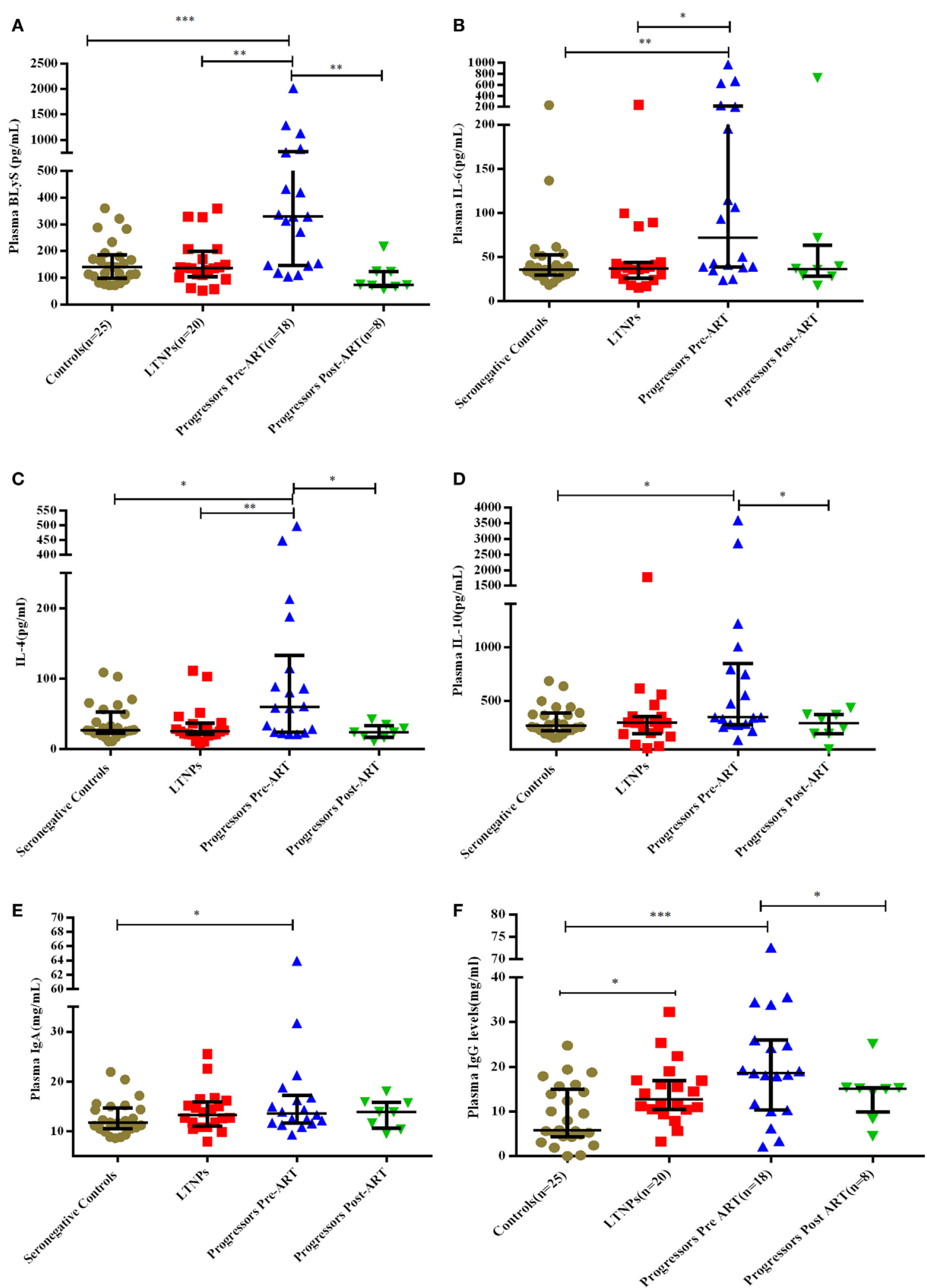

FIGURE 5 | Plasma concentration of B-cell growth factors and immunoglobulins in HIV-1 infected children at different disease stages of disease. (A-F) show levels of B lymphocyte stimulator (BLyS), IL-6, IL-4, IL-10, IgA, and IgG among 25 HIV-1 seronegative controls, 20 HIV-1-infected ART naive long-term non-progressors (LTNPS), 18 progressors pre-ART and 8 progressors post 6-12 months of ART. The $p$-values are based on Mann-Whitney $U$ test among seronegative donors, LTNPs, progressors pre-ART. Wilcoxon signed rank test was used for paired analysis of progressors pre-ART and post $6-12$ months of ART. The error bars indicate median values with interquartile range. ${ }^{\star} p \leq 0.05,{ }^{\star \star} p \leq 0.01,{ }^{\star \star *} p \leq 0.001$. 

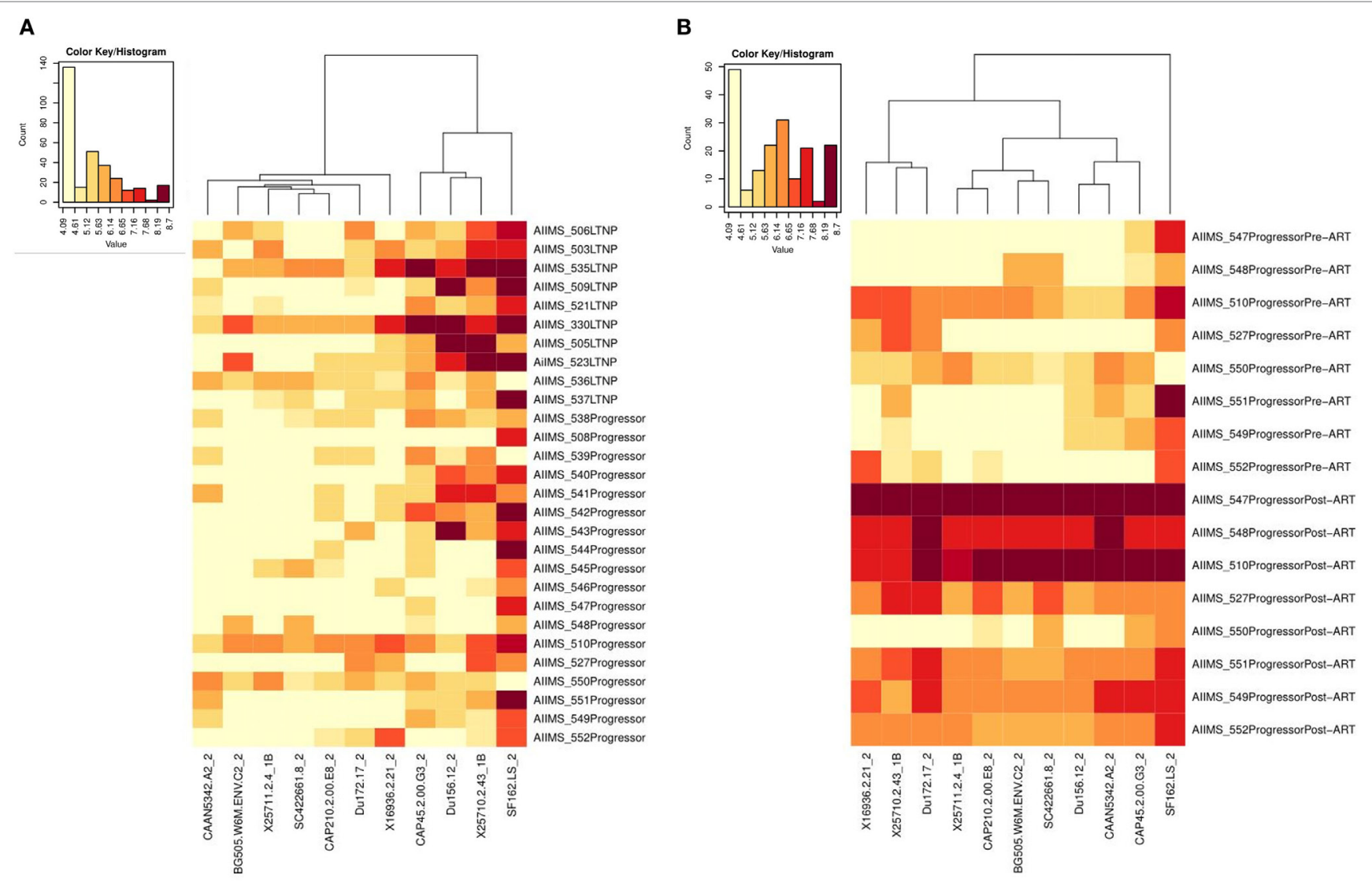

FIGURE 6 | Heat-map analysis of ID $\mathrm{D}_{50}$ titers of plasma samples from HIV-1-infected children based on hierarchical clustering and transformed natural log data of ID ${ }_{50}$ values. (A) shows comparison of $\mathrm{ID}_{50}$ titers of 10 ART naive long-term non-progressors (LTNPs) and 18 progressors, and (B) shows comparison of ID 50 titers of 8 progressors pre-ART and post 6-12 months of ART against a panel of 11 virus strains. In the heat-map, each row shows the natural log ID $\mathrm{D}_{50}$ values for each plasma sample, while the columns display the viruses. Darker color represents better neutralizing activity. Alpha numerals given after the underscore along with the viruses indicate the tier of the virus.

\section{Higher Levels of BLyS Correlated with Poor Viral Neutralization}

A significant negative correlation was observed between plasma levels of BLyS vs. GMTs ( $p=0.0016$ ) (Figure 8A) and \% viruses neutralized ( $p=0.0042$ ) (Figure 8B). High levels of BLyS in HIV-1 infected children may plausibly be one of contributory factors for poor viral neutralizing activity and faster disease progression in untreated progressors as compared to LTNPs with appropriate/basal levels of BLyS.

\section{DISCUSSION}

Antiretroviral therapy has to a great extent reduced motherto-child transmission, however, many children continue to become infected vertically; especially in resource limited settings. In 2016, 160,000 children acquired HIV-1 infection, majority being from low- and middle-income countries (42). Furthermore, only $43 \%$ of eligible children received HAART in 2016. If left untreated, most HIV-1-infected children die within 2 years of age, probably owing to their inability to mount adequate immune responses. Elucidating the underlying mechanisms of immunological deficits in HIV-1-infected children will help in designing effective interventional strategies. Earlier studies have reported defects in DCs leading to alterations in B cell subsets in HIV-1-infected individuals (30, 35, 43, 44). An inverse correlation between BLyS (BAFF) released by mDCs and $B$ cell numbers has been shown during primary HIV-1 infection (45). However, it is less clear how such alterations in DCs compromise B cell function in HIV-1 infection and disease progression.

B cell-associated cytokine CXCL13, has recently been proposed as a predictor for the development of cross nAbs in hyperacute HIV-1 C-infected women (29). The broadly neutralizing antibodies evolve after a minimum of 2-3 years of HIV-1 infection, only in a small subset of infected individuals $(46,47)$. It is important to delineate the factors promoting the development and persistence of such bnAbs in select individuals. Herein, we have the advantage of having a pediatric cohort comprising of antiretroviral naïve LTNPs with controlled disease 

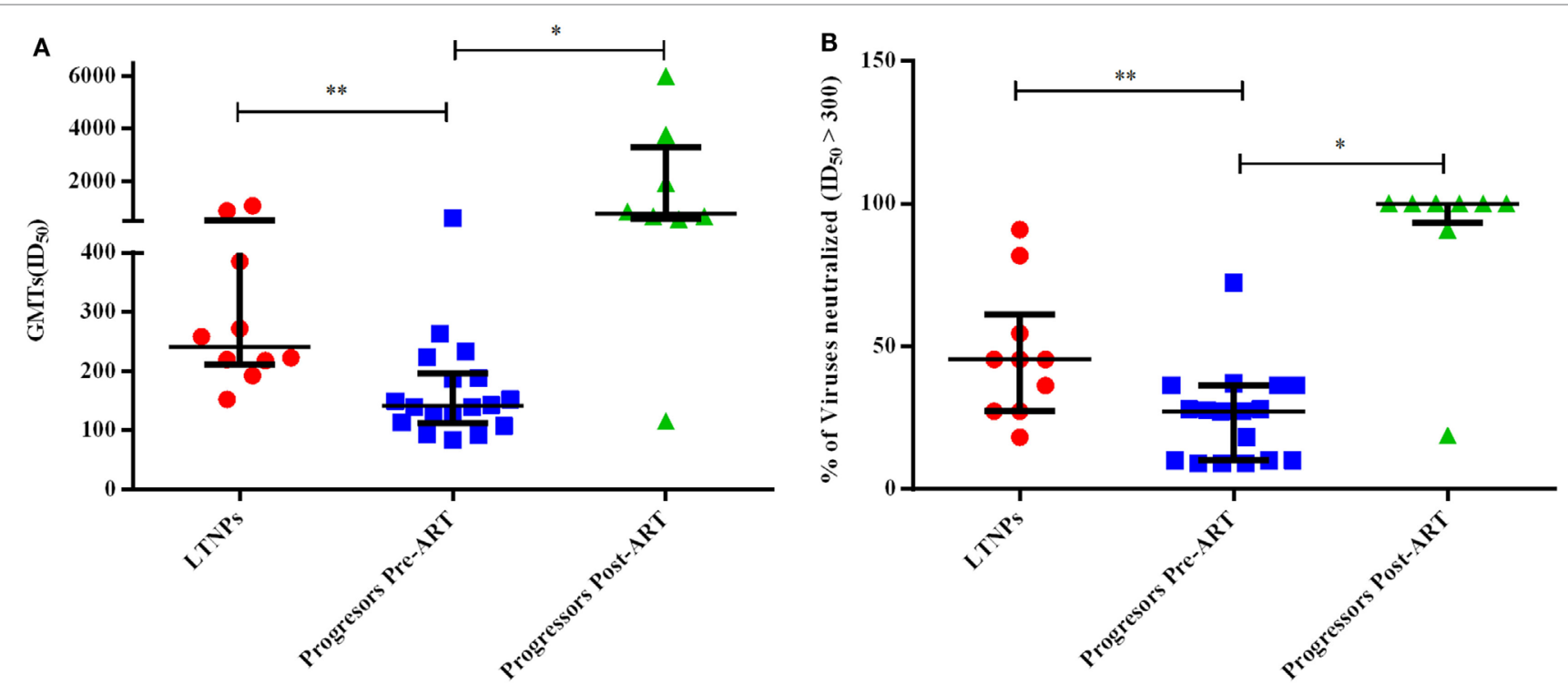

FIGURE 7 | Evaluation of neutralization potency and \% of viruses neutralized. (A) shows the comparison of geometric mean titers (GMTs), and (B) shows the comparison of $\%$ of viruses neutralized with $\mathrm{ID}_{50} \geq 300$ achieved amongst 10 ART naïve long-term non-progressors (LTNPs), 18 progressors pre-ART, and 8 progressors post 6-12 months of ART against a panel of 11 pseudoviruses. $p$-Values are based on Mann-Whitney $U$ test among seronegative donors, LTNPs, progressors pre-ART, Wilcoxon signed rank test was used for paired analysis of progressors pre-ART and post 6-12 months ART. The error bars show the median with the interquartile range. ${ }^{*} p \leq 0.05,{ }^{* *} p \leq 0.01$.
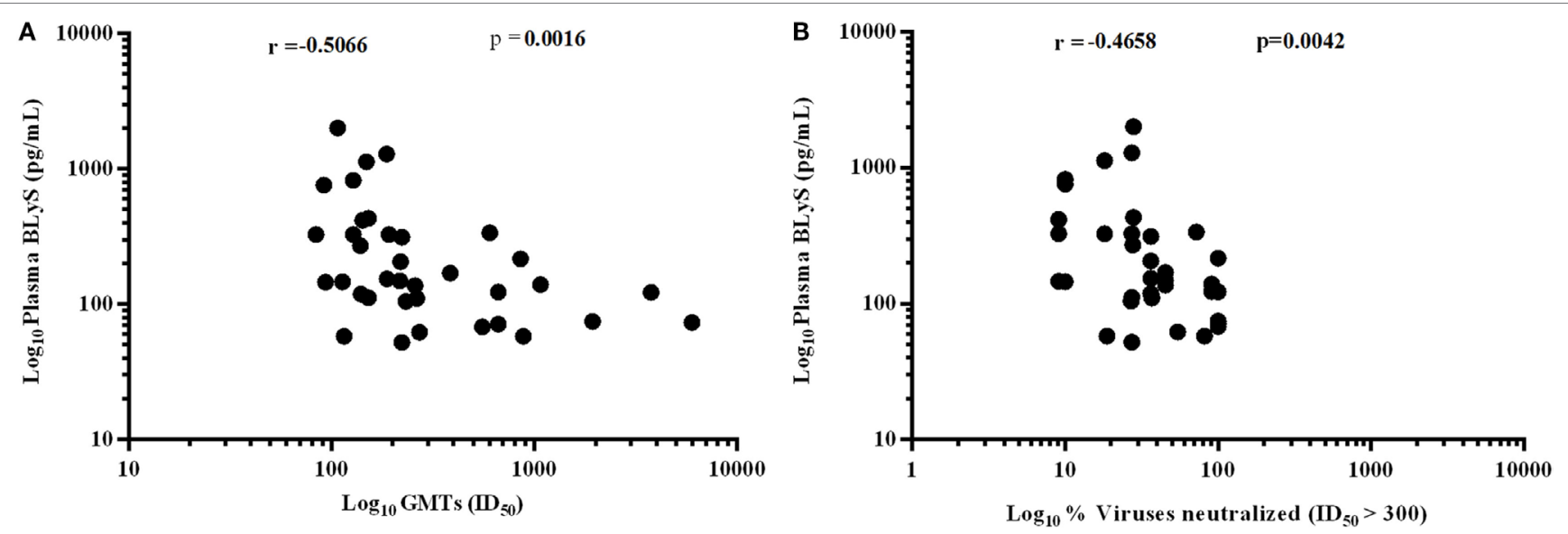

FIGURE 8 | Association of HIV-1-specific neutralization response with B lymphocyte stimulator (BLyS). (A) shows correlation of plasma levels of BLyS with geometric mean titers (GMTs), and (B) shows correlation of plasma BLyS with \% of viruses neutralized with $I D_{50} \geq 300$ against a panel of 11 pesudoviruses of different clades and tiers. Correlation coefficient ( $r$ ) was calculated using spearman rank correlation, for graphical representation $x$-axis, $y$-axis was converted to log scales.

and progressors, of which, a subset have been followed up post 6-12 months of ART. To the best of our knowledge, this is the first study conducted in subtype C HIV-1 chronically infected children, to show a link between altered expression of BLyS and antigen specific humoral immune response. The reduction in circulating DCs, resting memory B cells, and increase in MA and TLM B cells-associated with higher expression of BLyS in progressors of our study, is in accordance with that reported $(15,17,24,30,35,43,44)$. Recently, it has been shown in mice that BlyS excess is associated with expansion of immature B cells $(48,49)$. However, in our cohort, transitional immature B cells were observed only in six seronegative controls, two LTNPs, and five progressors (Table S3 in Supplementary Material), and the influence of high BLyS on this B cell population could not be inferred. Disease progression in HIV-1 infection involves a complex set of interactions between viral and host factors leading to a chronic immune activation state. Inflammation has been shown to be a contributing factor, in addition to $\mathrm{T}$ cell 
activation, towards disease progression and mortality (13). In viremic individuals, it has long been recognized that viral replication may not solely be responsible for disease progression; immune activation status being an important determinant too (3). High plasma levels of BLyS, IL-4, IL-6, and IL-10 observed in the progressors in this study along with B-cell dysregulation plausibly favor the overall inflammatory burden and impair viral neutralization efficiency. The expression and secretion of BLyS have been shown in vitro to be potentiated by inflammatory cytokines, such as IL-2, IL-10, TNF- $\alpha$, and IFN- $\gamma(50,51)$. Association of higher expression of BLyS on mDCs and plasma levels with lower \% of memory B cells and poor viral neutralizing activity in progressors suggests that high BLyS influences the survival, tissue distribution, and differentiation of B cells, thereby affecting the ultimate production of Ag-specific bnAbs. Among the other cytokines studied, only a weak negative correlation was found between plasma IL-4 levels and GMTs of neutralization in the infected children (Figure S4 in Supplementary Material). Sriram et al. showed that in vitro stimulation of murine bone marrow-derived conventional dendritic cells (cDCs) by TLR7/9 ligands in presence of IL-4, mediates suppression of antiviral responses (IFN $\beta$ and IFN-responsive genes), resulting in increased permissiveness of $\mathrm{cDCs}$ to viral infection (42). Similar observations herein of progressors with high viral load and high IL-4 levels correlating with poor viral neutralizing activity suggests the plausible involvement of IL-4 in antigenic persistence leading to polyclonal B cell activation and poor viral neutralizing activity.

Reduction in BLyS levels in the progressors post 6-12 months of ART and its correlation with increase in memory B cells and improvement in neutralizing activity, indicates that optimal levels of BLyS may be one of the determinants for maintain B cell functionality. Moreover, the high GMTs of neutralization in progressors post 6-12 months ART, reach levels similar/higher than that found in the LTNPs in this study and in a previous study (52-54). The influence of varying levels of BLyS and viral neutralizing efficiency (GMT) of nAbs needs to be further evaluated in a larger pre- and post-ART cohort of infected children. The limit number of follow ups herein is a drawback of our study. Rouers et al. (37) have observed that ECs naturally preserve their memory B cell compartments and maintain HIV-1 specific memory B cell responses with a broader cross neutralizing capacity. Further assessment of BLyS levels in such ECs would provide valuable information. Hypergammaglobulinemia was observed in infected children at different disease stages, with significantly higher plasma IgG levels in progressors than LTNPs in this study. Earlier reports suggest that IgGs in HIV-1 infected individuals are polyclonal in nature and there is loss of antigen-specific humoral immunity, as has also been observed by us (55).

Restoration of memory B cell responses in progressors post ART in this study is in agreement with previous studies documenting the beneficial effect of early initiation of ART $(23,44$, 56-58). In 2013, WHO conditionally recommended that all 2- to 5-year-old HIV-1-infected children be placed on HAART, based on studies that demonstrated improvement in clinical and virological parameters post ART (52). The present study furthers the beneficial effect of ART in early control of viremia in HIV-1-infected children and emphasizes the need to implement the new guidelines rigorously. Further, a detailed analysis of mDC subsets $\left(\mathrm{CD} 1 \mathrm{c}^{+}, \mathrm{CD} 141^{+}\right)$and monocytes contributing to HIV-1-specific B cell subsets (59), and their function will provide significant insight in this direction.

To summarize, a compromised B cell compartment and high levels of BLyS correlated with poor viral neutralizing Ab response in HIV-1-infected pediatric progressors. Our findings suggest that modulation of BLyS expression may be considered for therapeutic interventional strategies to prevent $\mathrm{B}$ cell dysfunction and systemic immune activation, that are the hallmarks of HIV-1 disease progression.

\section{ETHICS STATEMENT}

The study was approved by the "Institute Ethics Committee" All India Institute of Medical Sciences (AIIMS), New Delhi (IEC/ NP-269/2012 \& RP-39/2012). All the experiments were carried out in accordance with relevant institutional ethics committee guidelines and regulations. Written informed signed consent forms were obtained from the parents/guardians of all the study subjects.

\section{AUTHOR CONTRIBUTIONS}

KL conceived and designed the study, edited and finalized the manuscript. RL, SKK, BD, and RS provided the HIV-1-infected pediatric samples. MS and KS provided the seronegative control samples. HA performed the research, data analyses, and wrote the manuscript. OC helped HA in flow-cytometry experiments. LK, SK, MM, and HA performed neutralization assays and contributed to manuscript editing. NM performed some of the ELISA experiments.

\section{ACKNOWLEDGMENTS}

The authors thank all the study participants in this study and the clinical/technical staff at the Department of Pediatrics, AIIMS, New Delhi, India for providing specimens. Technical assistance from Mr. Abdul Wahid Hussain is highly acknowledged. We also thank the NIH-AIDS Research and Reference Reagent Program (NIH ARRRP) for many reagents used in this study.

\section{FUNDING}

This study was funded by the Department of Biotechnology (DBT) (\# BT/PR5758/MED/29/591/2012) and Science and Engineering Research Board-Department of Science and technology (SERBDST), India (EMR/2015/001276). HA is supported by a Senior Research Fellowship from the Council of Scientific and Industrial Research, Govt. of India.

\section{SUPPLEMENTARY MATERIAL}

The Supplementary Material for this article can be found online at http://www.frontiersin.org/article/10.3389/fimmu.2017.01697/ full\#supplementary-material. 


\section{REFERENCES}

1. Pereyra F, Addo MM, Kaufmann DE, Liu Y, Miura T, Rathod A, et al. Genetic and immunologic heterogeneity among persons who control HIV infection in the absence of therapy. J Infect Dis (2008) 197(4):563-71. doi:10.1086/526786

2. Adland E, Paioni P, Thobakgale C, Laker L, Mori L, Muenchhoff M, et al. Discordant impact of HLA on viral replicative capacity and disease progression in pediatric and adult HIV infection. PLoS Pathog (2015) 11(6):e1004954. doi:10.1371/journal.ppat.1004954

3. Muenchhoff M, Adland E, Karimanzira O, Crowther C, Pace M, Csala A, et al. Nonprogressing HIV-infected children share fundamental immunological features of nonpathogenic SIV infection. Sci Transl Med (2016) 8(358):358ra125. doi:10.1126/scitranslmed.aag 1048

4. Devi NP, Shenbagavalli R, Ramesh K, Rathinam SN, Swaminathan S. Rapid progression of HIV infection in infancy. Indian Pediatr (2009) 46(1):53-6.

5. Ferrand RA, Corbett EL, Wood R, Hargrove J, Ndhlovu CE, Cowan FM, et al. AIDS among older children and adolescents in Southern Africa: projecting the time course and magnitude of the epidemic. AIDS (2009) 23(15):2039-46. doi:10.1097/QAD.0b013e32833016ce

6. Richardson BA, Mbori-Ngacha D, Lavreys L, John-Stewart GC, Nduati R, Panteleeff DD, et al. Comparison of human immunodeficiency virus type 1 viral loads in Kenyan women, men, and infants during primary and early infection. J Virol (2003) 77(12):7120-3. doi:10.1128/JVI.77.12.7120-7123.2003

7. Muenchhoff M, Prendergast AJ, Goulder PJ. Immunity to HIV in early life. Front Immunol (2014) 5:391. doi:10.3389/fimmu.2014.00391

8. Tobin NH, Aldrovandi GM. Immunology of pediatric HIV infection. Immunol Rev (2013) 254(1):143-69. doi:10.1111/imr.12074

9. Kumar P. Long term non-progressor (LTNP) HIV infection. Indian J Med Res (2013) 138(3):291-3.

10. Hoover DR, Graham NM, Chen B, Taylor JM, Phair J, Zhou SY, et al. Effect of CD4+ cell count measurement variability on staging HIV-1 infection. J Acquir Immune Defic Syndr (1992) 5(8):794-802. doi:10.1097/ 00126334-199208000-00005

11. Gianesin K, Petrara R, Freguja R, Zanchetta M, Giaquinto C, De Rossi A. Host factors and early treatments to restrict paediatric HIV infection and early disease progression. J Virus Erad (2015) 1(3):140-7.

12. Freguja R, Gianesin K, Zanchetta M, De Rossi A. Cross-talk between virus and host innate immunity in pediatric HIV-1 infection and disease progression. New Microbiol (2012) 35(3):249-57.

13. Pananghat AN, Aggarwal H, Prakash SS, Makhdoomi MA, Singh R, Lodha R, et al. IL-8 alterations in HIV-1 infected children with disease progression. Medicine (2016) 95(21):e3734. doi:10.1097/MD.0000000000003734

14. Manches O, Frleta D, Bhardwaj N. Dendritic cells in progression and pathology of HIV infection. Trends Immunol (2014) 35(3):114-22. doi:10.1016/ j.it.2013.10.003

15. Poudrier J, Roger M. Dendritic cell status modulates the outcome of HIVrelated B cell disease progression. PLoS Pathog (2011) 7(8):e1002154. doi:10.1371/journal.ppat.1002154

16. Banchereau J, Briere F, Caux C, Davoust J, Lebecque S, Liu YJ, et al. Immunobiology of dendritic cells. Annu Rev Immunol (2000) 18:767-811. doi:10.1146/annurev.immunol.18.1.767

17. Selvaraj A, Pilakka-Kanthikeel S, Bhavani PK, Hanna LE, Pahwa S, Swaminathan S. Defective dendritic cell response to toll-like receptor $7 / 8$ agonists in perinatally HIV-infected children. Pathog Dis (2013) 69(3):184-93. doi:10.1111/2049-632X.12067

18. Zhang Z, Wang FS. Plasmacytoid dendritic cells act as the most competent cell type in linking antiviral innate and adaptive immune responses. Cell Mol Immunol (2005) 2(6):411-7.

19. Dutertre CA, Amraoui S, DeRosa A, Jourdain JP, Vimeux L, Goguet M, et al. Pivotal role of M-DC8(+) monocytes from viremic HIV-infected patients in TNFalpha overproduction in response to microbial products. Blood (2012) 120(11):2259-68. doi:10.1182/blood-2012-03-418681

20. Collin M, McGovern N, Haniffa M. Human dendritic cell subsets. Immunology (2013) 140(1):22-30. doi:10.1111/imm.12117

21. Chaudhary O, Bala M, Singh J, Hazarika A, Kumar R, Luthra K. The DC-SIGNR 7/5 genotype is associated with high dendritic cell counts and their subsets in patients infected with HIV-1. J Clin Immunol (2013) 33(4): 788-97. doi:10.1007/s10875-013-9868-3
22. Dutertre CA, Jourdain JP, Rancez M, Amraoui S, Fossum E, Bogen B, et al. TLR3-responsive, XCR1+, CD141(BDCA-3)+/CD8alpha+-equivalent dendritic cells uncovered in healthy and simian immunodeficiency virusinfected rhesus macaques. J Immunol (2014) 192(10):4697-708. doi:10.4049/ jimmunol.1302448

23. Moir S, Buckner CM, Ho J, Wang W, Chen J, Waldner AJ, et al. B cells in early and chronic HIV infection: evidence for preservation of immune function associated with early initiation of antiretroviral therapy. Blood (2010) 116(25):5571-9. doi:10.1182/blood-2010-05-285528

24. Moir S, Fauci AS. B cells in HIV infection and disease. Nat Rev Immunol (2009) 9(4):235-45. doi:10.1038/nri2524

25. Moir S, Fauci AS. Insights into B cells and HIV-specific B-cell responses in HIV-infected individuals. Immunol Rev (2013) 254(1):207-24. doi:10.1111/ imr. 12067

26. Bussmann BM, Reiche S, Bieniek B, Krznaric I, Ackermann F, Jassoy C. Loss of HIV-specific memory B-cells as a potential mechanism for the dysfunction of the humoral immune response against HIV. Virology (2010) 397(1):7-13. doi:10.1016/j.virol.2009.11.003

27. Cagigi A, Nilsson A, De Milito A, Chiodi F. B cell immunopathology during HIV-1 infection: lessons to learn for HIV-1 vaccine design. Vaccine (2008) 26(24):3016-25. doi:10.1016/j.vaccine.2007.11.063

28. Pensieroso S, Galli L, Nozza S, Ruffin N, Castagna A, Tambussi G, et al. B-cell subset alterations and correlated factors in HIV-1 infection. AIDS (2013) 27(8):1209-17. doi:10.1097/QAD.0b013e32835edc47

29. Mabuka JM, Dugast AS, Muema DM, Reddy T, Ramlakhan Y, Euler Z, et al. Plasma CXCL13 but not B cell frequencies in acute HIV infection predicts emergence of cross-neutralizing antibodies. Front Immunol (2017) 8:1104 doi:10.3389/fimmu.2017.01104

30. Fontaine J, Chagnon-Choquet J, Valcke HS, Poudrier J, Roger M. High expression levels of B lymphocyte stimulator (BLyS) by dendritic cells correlate with HIV-related B-cell disease progression in humans. Blood (2011) 117(1):145-55. doi:10.1182/blood-2010-08-301887

31. Schuh E, Musumeci A. Human plasmacytoid dendritic cells display and shed B cell maturation antigen upon TLR engagement. J Immunol (2017) 198(8):3081-8. doi:10.4049/jimmunol.1601746

32. Poudrier J, Chagnon-Choquet J, Roger M. Influence of dendritic cells on B-cell responses during HIV infection. Clin Dev Immunol (2012) 2012 : 592187. doi:10.1155/2012/592187

33. Goo L, Chohan V, Nduati R, Overbaugh J. Early development of broadly neutralizing antibodies in HIV-1-infected infants. Nat Med (2014) 20(6): 655-8. doi:10.1038/nm.3565

34. von Bredow B, Arias JF, Heyer LN, Moldt B, Le K, Robinson JE, et al. Comparison of antibody-dependent cell-mediated cytotoxicity and virus neutralization by HIV-1 Env-specific monoclonal antibodies. J Virol (2016) 90(13):6127-39. doi:10.1128/JVI.00347-16

35. Sabourin-Poirier C, Fourcade L, Chagnon-Choquet J, Labbe AC, Alary M, Guedou F, et al. Blood B lymphocyte stimulator (BLyS)/BAFF levels may reflect natural immunity to HIV in highly exposed uninfected Beninese Commercial Sex Workers. Sci Rep (2016) 6:32318. doi:10.1038/srep32318

36. Zhang Z, Fu J, Zhao Q, He Y, Jin L, Zhang H, et al. Differential restoration of myeloid and plasmacytoid dendritic cells in HIV-1-infected children after treatment with highly active antiretroviral therapy. J Immunol (2006) 176(9):5644-51. doi:10.4049/jimmunol.176.9.5644

37. Rouers A, Klingler J, Su B, Samri A, Laumond G, Even S, et al. HIV-specific $B$ cell frequency correlates with neutralization breadth in patients naturally controlling HIV-infection. EBioMedicine (2017) 21:158-69. doi:10.1016/ j.ebiom.2017.05.029

38. Mellors JW, Munoz A, Giorgi JV, Margolick JB, Tassoni CJ, Gupta P, et al. Plasma viral load and CD4+ lymphocytes as prognostic markers of HIV-1 infection. Ann Intern Med (1997) 126(12):946-54. doi:10.7326/0003-4819126-12-199706150-00003

39. Phillips AN. CD4 lymphocyte depletion prior to the development of AIDS. AIDS (1992) 6(7):735-6. doi:10.1097/00002030-199207000-00018

40. Montefiori DC. Measuring HIV neutralization in a luciferase reporter gene assay. Methods Mol Biol (2009) 485:395-405. doi:10.1007/978-1-59745170-3_26

41. Seaman MS, Janes H, Hawkins N, Grandpre LE, Devoy C, Giri A, et al. Tiered categorization of a diverse panel of HIV-1 Env pseudoviruses 
for assessment of neutralizing antibodies. J Virol (2010) 84(3):1439-52. doi:10.1128/JVI.02108-09

42. Sriram U, Xu J, Chain RW, Varghese L, Chakhtoura M, Bennett HL, et al. IL-4 suppresses the responses to TLR7 and TLR9 stimulation and increases the permissiveness to retroviral infection of murine conventional dendritic cells. PLoS One (2014) 9(1):e87668. doi:10.1371/journal.pone.0087668

43. Poudrier J, Soulas C, Chagnon-Choquet J, Burdo T, Autissier P, Oskar K, et al. High expression levels of BLyS/BAFF by blood dendritic cells and granulocytes are associated with B-cell dysregulation in SIV-infected rhesus macaques. PLoS One (2015) 10(6):e0131513. doi:10.1371/journal. pone. 0131513

44. Muema DM, Macharia GN, Hassan AS, Mwaringa SM, Fegan GW, Berkley JA, et al. Control of viremia enables acquisition of resting memory $B$ cells with age and normalization of activated B cell phenotypes in HIV-infected children. J Immunol (2015) 195(3):1082-91. doi:10.4049/jimmunol.1500491

45. Borhis G, Burelout C, Chaoul N, Smith N, Goujard C, Meyer L, et al. Plasmacytoid dendritic cells and myeloid cells differently contribute to B-cell-activating factor belonging to the tumor necrosis factor superfamily overexpression during primary HIV infection. AIDS (2016) 30(3):365-76. doi:10.1097/QAD.0000000000000965

46. Landais E, Huang X, Havenar-Daughton C, Murrell B, Price MA, Wickramasinghe $\mathrm{L}$, et al. Broadly neutralizing antibody responses in a large longitudinal sub-Saharan HIV primary infection cohort. PLoS Pathog (2016) 12(1):e1005369. doi:10.1371/journal.ppat.1005369

47. Euler Z, Schuitemaker H. Cross-reactive broadly neutralizing antibodies: timing is everything. Front Immunol (2012) 3:215. doi:10.3389/fimmu. 2012.00215

48. Jacobs HM, Thouvenel CD, Leach S, Arkatkar T, Metzler G, Scharping NE, et al. Cutting edge: BAFF promotes autoantibody production via TACIdependent activation of transitional B cells. J Immunol (2016) 196(9):3525-31. doi:10.4049/jimmunol.1600017

49. Malaspina A, Moir S, Ho J, Wang W, Howell ML, O’Shea MA, et al. Appearance of immature/transitional B cells in HIV-infected individuals with advanced disease: correlation with increased IL-7. Proc Natl Acad Sci U S A (2006) 103(7):2262-7. doi:10.1073/pnas.0511094103

50. Cancro MP, D'Cruz DP, Khamashta MA. The role of B lymphocyte stimulator (BLyS) in systemic lupus erythematosus. J Clin Invest (2009) 119(5): 1066-73. doi:10.1172/JCI38010

51. Nardelli B, Belvedere O, Roschke V, Moore PA, Olsen HS, Migone TS, et al. Synthesis and release of B-lymphocyte stimulator from myeloid cells. Blood (2001) 97(1):198-204. doi:10.1182/blood.V97.1.198

52. Makhdoomi MA, Khan L, Kumar S, Aggarwal H, Singh R, Lodha R, et al. Evolution of cross-neutralizing antibodies and mapping epitope specificity in plasma of chronic HIV-1-infected antiretroviral therapy-naive children from India. J Gen Virol (2017) 98(7):1879-91. doi:10.1099/jgv.0.000824

53. Prakash SS, Chaudhary AK, Lodha R, Kabra SK, Vajpayee M, Hazarika A, et al. Efficient neutralization of primary isolates by the plasma from HIV-1 infected Indian children. Viral Immunol (2011) 24(5):409-13. doi:10.1089/ vim. 2011.0028

54. Andrabi R, Bala M, Kumar R, Wig N, Hazarika A, Luthra K. Neutralization of tier-2 viruses and epitope profiling of plasma antibodies from human immunodeficiency virus type 1 infected donors from India. PLoS One (2012) 7(8):e43704. doi:10.1371/journal.pone.0043704

55. De Milito A, Nilsson A, Titanji K, Thorstensson R, Reizenstein E, Narita M, et al. Mechanisms of hypergammaglobulinemia and impaired antigenspecific humoral immunity in HIV-1 infection. Blood (2004) 103(6):2180-6. doi:10.1182/blood-2003-07-2375

56. Amu S, Lavy-Shahaf G, Cagigi A, Hejdeman B, Nozza S, Lopalco L, et al. Frequency and phenotype of B cell subpopulations in young and aged HIV-1 infected patients receiving ART. Retrovirology (2014) 11:76. doi:10.1186/ s12977-014-0076-x

57. Pogliaghi M, Ripa M, Pensieroso S, Tolazzi M, Chiappetta S, Nozza S, et al. Beneficial Effects of cART Initiated during primary and chronic HIV-1 infection on immunoglobulin-expression of memory B-cell subsets. PLoS One (2015) 10(10):e0140435. doi:10.1371/journal.pone.0140435

58. Tanko RF, Soares AP, Müller TL, Garrett NJ, Samsunder N, Abdool Karim Q, et al. Effect of antiretroviral therapy on the memory and activation profiles of B cells in HIV-infected African women. J Immunol (2017) 198(3):1220-8. doi:10.4049/jimmunol.1601560

59. Moir S, Ho J, Malaspina A, Wang W, DiPoto AC, O'Shea MA, et al. Evidence for HIV-associated B cell exhaustion in a dysfunctional memory B cell compartment in HIV-infected viremic individuals. J Exp Med (2008) 205(8): 1797-805. doi:10.1084/jem.20072683

Conflict of Interest Statement: The authors declare that the research was conducted in the absence of any commercial or financial relationships that could be construed as a potential conflict of interest.

Copyright (® 2017 Aggarwal, Khan, Chaudhary, Kumar, Makhdoomi, Singh, Sharma, Mishra, Lodha, Srinivas, Das, Kabra and Luthra. This is an open-access article distributed under the terms of the Creative Commons Attribution License (CC BY). The use, distribution or reproduction in other forums is permitted, provided the original author(s) or licensor are credited and that the original publication in this journal is cited, in accordance with accepted academic practice. No use, distribution or reproduction is permitted which does not comply with these terms. 